\title{
Haemodynamic changes induced by prostacyclin in man
}

\author{
JERZY SZCZEKLIK, ANDRZEJ SZCZEKLIK, RAFAE NIZANKOWSKI \\ From the Institute of Internal Medicine, Copernicus Academy of Medicine, Cracow, Poland
}

SUMMARY Intra-arterial or intravenous infusion of prostacyclin at three dose levels $(2,5$, and $10 \mathrm{ng} /$ $\mathrm{kg}$ per $\mathrm{min}$ ) in 10 subjects without evidence of coronary heart disease or cardiac failure, led to a distinct fall in peripheral and total pulmonary vascular resistances. This was accompanied by a drop in intra-arterial blood pressure, and the acceleration of heart rate. Stroke volume, cardiac output, mean right atrial pressure, and left ventricular end-diastolic pressure showed no significant changes. Except for sporadic headache no side effects occurred. Prostacyclin appears to act predominantly on resistance vessels. The haemodynamic effects produced by prostacyclin in man might be of clinical interest in the treatment of conditions associated with a significant rise in vascular resistance.

Prostacyclin $\left(\mathrm{PGI}_{2}\right)$ is a metabolite of arachidonic acid, generated by the arterial walls ${ }^{12}$ and secreted into the circulation by the lungs. ${ }^{3}$ In man, it blocks platelet aggregation, disperses circulating platelet aggregates, and causes vasodilatation. ${ }^{4}$ It might well be that prostacyclin shields arteries against mural thrombosis and stops development of atherosclerosis. ${ }^{5}$

The remarkable properties of prostacyclin have been found beneficial in treating advanced arteriosclerosis obliterans. ${ }^{6}$ They could also be useful in the management of atherosclerotic heart disease provided more was known about the haemodynamic effects of prostaglandin in man.

\section{Patients and methods}

The study included 10 men, aged 34 to 65 years, who underwent treatment with prostacyclin because of peripheral arterial disease. Arteriosclerosis obliterans was diagnosed in seven of them, and thrombangiitis in the remaining three. The diagnosis was based on typical history, clinical examination, and in each case it was confirmed by angiography. There was no evidence of either coronary heart disease or cardiac failure.

The patients had not received any drugs for a period of about a week preceding the infusion. The study was carried out in the intensive care unit under continuous electrocardiographic monitoring.

Cooled solution of lyophilised sodium salt of prostacyclin (synthesised by The Upjohn ComReceived for publication 30 January 1980 pany, Kalamazoo, Michigan, USA, and formulated by The Wellcome Research Laboratories, Beckenham, England) in glycine buffer $\mathrm{pH} 10.5$ was infused during 72 hours. Six patients (cases 1, 2, $3,7,9$, and 10) received infusions into the femoral artery of the affected limb, four others (cases 4, 5, 6 , and 8 ) into the subclavian vein. The initial dose of $2 \mathrm{ng} / \mathrm{kg}$ per min was stepped up, first to $5 \mathrm{ng} / \mathrm{kg}$ per min and then to $10 \mathrm{ng} / \mathrm{kg}$ per min.

Right heart catheterisation was carried out with a 7F Swan-Ganz flow-directed thermodilution catheter, inserted through a cutdown in an ante-
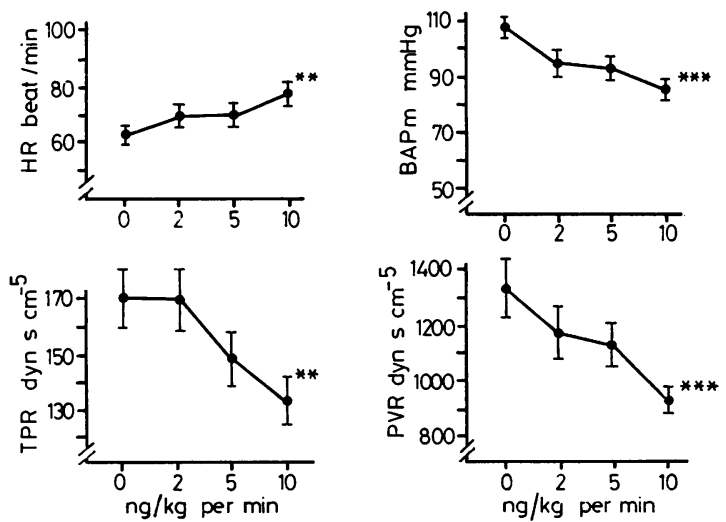

Fig. The effects of prostacyclin infusion on heart rate $(H R)$, mean brachial artery pressure $(B A P m)$, total pulmonary resistance (TPR), and peripheral vascular resistance (PVR). 

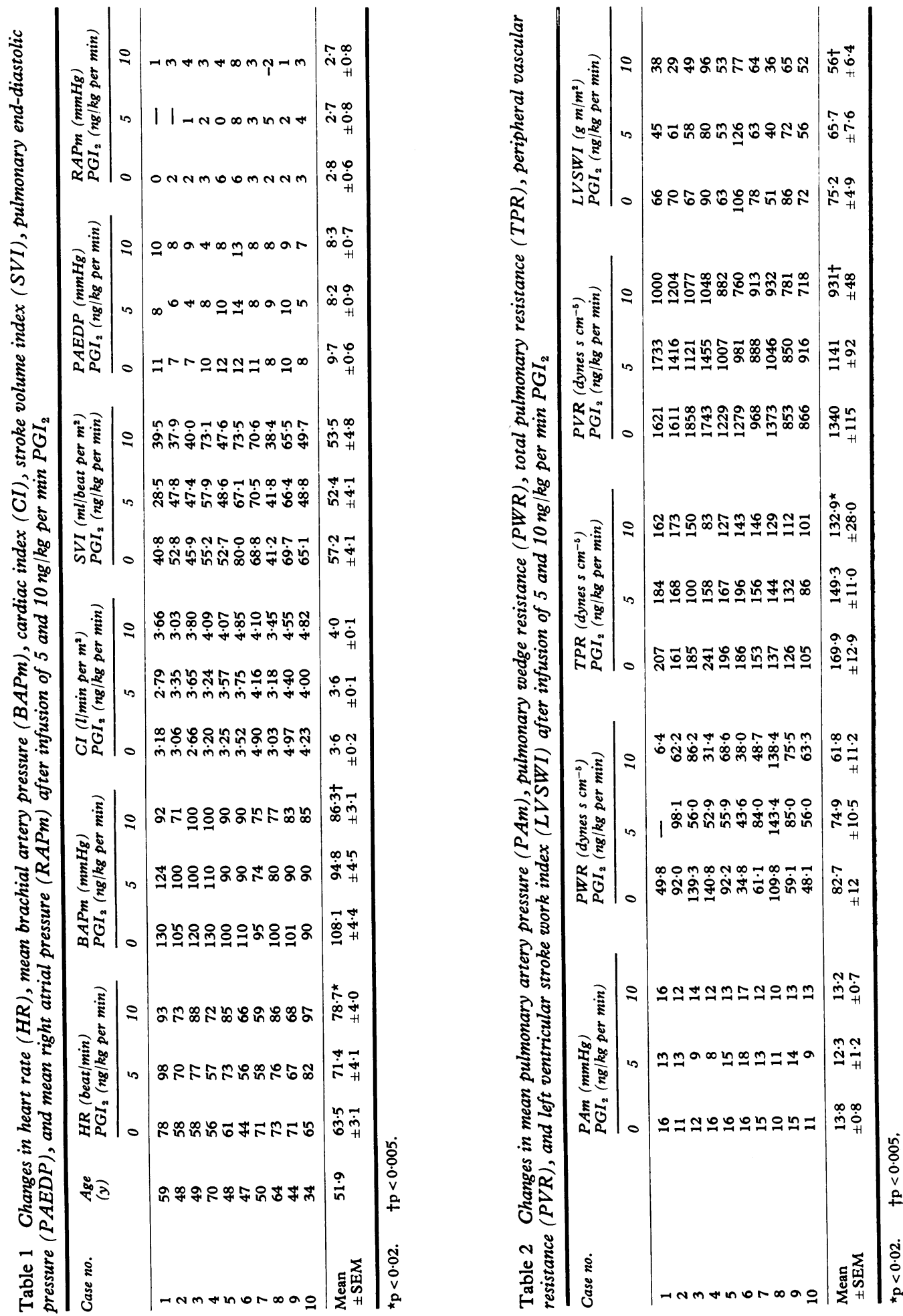
cubital vein. The catheter was connected to a 756 pressure transducer and 863 amplifier of Mingograf 82 recorder (Elema-Siemens) from which measurements of right atrial, right ventricular, pulmonary artery, and pulmonary capillary wedge pressures were made. Cardiac output was measured using the thermodilution technique in triplicate, and the mean was calculated. Arterial blood pressure was determined continuously through a cannula inserted into the left brachial artery.

Cardiac output, stroke volume, and both left and right ventricular stroke work were expressed as indices by dividing by body surface. In calculating the left ventricular stroke work index pulmonary artery end-diastolic pressure was used instead of left ventricular end-diastolic pressure. Peripheral vascular resistance, total pulmonary resistance, and pulmonary wedge resistance were calculated by the standard formulae.

Simultaneously, external systolic time intervals were measured from the carotid artery and praecordial phonocardiogram and electrocardiogram. The differences between time intervals after correction for standard heart rate were compared. ${ }^{7}$ Left ventricular $\mathrm{dP} / \mathrm{dt}_{\max }$ was calculated by the indirect method $^{8}$ using the following formula for mean electromechanical $\Delta \mathrm{p} / \Delta \mathrm{t}: \mathrm{BPd}-\mathrm{PAEDP} / \mathrm{PEP}$, where $\mathrm{BPd}$ is diastolic blood pressure in the brachial artery, PAEDP is pulmonary artery end-diastolic pressure, and PEP is pre-ejection period.

Additionally, in three of 10 patients both resting and hyperaemic calf muscle blood flows in the affected limbs were measured according to Lassen et al., as described previously, ${ }^{6}$ and expressed in $\mathrm{ml}$ per min per $100 \mathrm{~g}$.

Student's $t$ test for unpaired data was used in statistical evaluation.

\section{Results}

In all 10 patients the initial haemodynamic values studied were within the normal range, except for decreased resting and hyperaemic muscle blood flow. The changes in certain haemodynamic indices appeared early during infusion of the lowest dose of $\mathrm{PGI}_{2}$. These changes became more pronounced with the increase in dose of the infused hormone. $\mathrm{PGI}_{2}$ at a dose of $10 \mathrm{ng} / \mathrm{kg}$ per min caused a distinct fall in pulmonary vascular resistance from 1340 to 932 dynes $\mathrm{s} \mathrm{cm}^{-5}(\mathrm{p}<0.01)$. At the same time arterial blood pressure (mean, systolic, and diastolic) fell on average by 20 per cent. Heart rate rose from mean $63 /$ minute to $79 /$ minute $(p<0.01)$, while left ventricular stroke work index declined from 75 to $56 \mathrm{~g} \mathrm{~m} / \mathrm{m}^{2}$ (p $<0.05)$. There was a mild, insignificant decrease by 12 per cent in pulmonary wedge resistance. Total pulmonary resistance, however, fell significantly $(p<0.05)$ from mean 170 to 133 dynes s cm$~^{-5}$. The following indices remained unaffected by the administration of $\mathrm{PGI}_{2}$ : cardiac output, cardiac index, stroke volume index, pulmonary artery enddiastolic pressure, and right atrial pressure. Mean electromechanical $\Delta p / \Delta t$ showed no changes during infusion of 2 and $5 \mathrm{ng} / \mathrm{kg}$ per $\min \mathrm{PGI}_{2}$, and fell during the administration of $10 \mathrm{ng} / \mathrm{kg}$ per min $\mathrm{PGI}_{2}$. Systolic time intervals remained unchanged throughout $\mathrm{PGI}_{2}$ infusion. Hyperaemic muscle blood flow increased in the affected limbs (from $3.3 \pm 0.7$ to $11.9 \pm 3.0 \mathrm{ml} / \mathrm{min}$ per $100 \mathrm{~g}$ at $10 \mathrm{ng} / \mathrm{kg}$ per $\min \mathrm{PGI}_{2}$ ).

The route of administration of $\mathrm{PGI}_{2}$ did not seem to affect the haemodynamic indices studied, which showed similar changes in patients receiving intra-arterial or intravenous infusions. In some patients prolonged infusion of high doses of $\mathrm{PGI}_{2}$ caused headache or pain in the leg. Decrease in dose resulted in rapid disappearance of these symptoms. No other side effects occurred.

\section{Discussion}

Vasodilatory properties of $\mathrm{PGI}_{2}$ described in man previously ${ }^{9}$ explain several of the haemodynamic findings reported here. Of these, a pronounced fall in vascular resistance was the most striking phenomenon. This fall included pulmonary vascular resistance and total pulmonary resistance. It occurred even during infusion of the lowest dose of $\mathrm{PGI}_{2}$, progressed in a dose-dependent manner, and was accompanied by a distinct rise in muscle blood flow. These effects were most striking in the subjects with basic pulmonary vascular resistance values close to the upper limit of the normal range. Thus, in four patients with basic values between 1500 to 1800 dynes $\mathrm{s} \mathrm{cm}^{-5}$ pulmonary vascular resistance fell on average by 40 per cent, while in the remaining six patients (basic values below 1500 dynes $\mathrm{s} \mathrm{cm}^{-5}$ ) it declined by only 24 per cent.

A similar dose-dependent fall in pulmonary vascular resistance after $\mathrm{PGI}_{2}$ injection was reported recently in several experimental animal models. ${ }^{10} 11$ Man, however, appears to be more sensitive to $\mathrm{PGI}_{2}$ than the animals studied. Infusion of five to 10 times lower concentrations of prostacyclin to man than to the animals ${ }^{101213}$ resulted in a similar fall in pulmonary vascular resistance in both groups.

In comparison to prostaglandin $\mathrm{E}_{1}\left(\mathrm{PGE}_{1}\right)$ prostacyclin has a stronger vasodilatatory action in man. Doses of $\mathrm{PGE}_{1}{ }^{14}$ at least twice as high were necessary to reduce pulmonary vascular resistance to the range similar to that reported here. Prostacy- 
clin was also better tolerated than $\mathrm{PGE}_{1}$. We have not observed abdominal cramps or back pain, which were frequently recorded in subjects receiving $\mathrm{PGE}_{1}$, and which had necessitated interruption of the infusion. ${ }^{15}$

Although $\mathrm{PGI}_{2}$ depressed significantly total pulmonary resistance, its effects on the pulmonary bed were less pronounced than those on peripheral vascular resistance. Thus, during the administration of $\mathrm{PGI}_{2}$ at a dose of $10 \mathrm{ng} / \mathrm{kg}$ per min pulmonary wedge resistance fell by 12.5 per cent, total pulmonary resistance by 21.7 per cent, and peripheral vascular resistance by 30.4 per cent-in comparison with initial values. Similarly, Kadowitz et al. ${ }^{16}$ obtained a more pronounced fall in systemic than pulmonary vascular resistance in dogs receiving $\mathrm{PGI}_{2}$. Though neither in animals nor in men were these differences of striking magnitude, they nevertheless might suggest that the two vascular beds vary in sensitivity to $\mathrm{PGI}_{2}$. This observation seems interesting, since the sensitivity to the vasodilatating action of prostaglandins varies between the different vascular regions, being highest in the skeletal muscle vasculature and lowest in the splanchnic vascular bed. Moreover, in the skeletal muscle vascular bed, the $\mathrm{PGI}_{2}$ synthetic pathway is quantitatively the most important. ${ }^{17}$

The falling vascular resistance caused a drop in arterial blood pressure, reaching the level of significance at a dose $10 \mathrm{ng} / \mathrm{kg}$ per min. The acceleration of heart rate, which followed, could be looked upon as an autoregulatory mechanism, triggered by a fall in blood pressure. This acceleration together with a slight fall in stroke volume index resulted in the small increase in cardiac index, which did not reach the level of statistical significance. Left ventricular stroke work index decreased significantly during infusion of $10 \mathrm{ng} / \mathrm{kg}$ per min $\mathrm{PGI}_{2}$. Lower doses of $\mathrm{PGI}_{2}$ (2 and 5 $\mathrm{ng} / \mathrm{kg}$ per $\mathrm{min}$ ), which did not reduce afterload, however, caused no changes in either left ventricular stroke work index or cardiac index, left ventricular $\Delta \mathrm{p} / \Delta \mathrm{t}$, and systolic time interval. It appears, therefore, that $\mathrm{PGI}_{2}$ in the above doses has no direct inotropic effects.

Our overall impression is that prostacyclin acts predominantly on the resistance vessels. This suggestion stems from the following haemodynamic changes occurring during $\mathrm{PGI}_{2}$ infusion: (1) fall in vascular resistance; (2) increase in muscle blood flow; (3) lack of changes in mean right atrial pressure. Prostacyclin, therefore, could be valuable not only in the treatment of peripheral arterial disease, ${ }^{6} 18$ but also in clinical conditions associated with significant rise in vascular resistance, including pulmonary hypertension, hypertensive emergencies, and cardiogenic shock. Clinical studies with prostacyclin seem warranted in heart failure, a condition affected favourably by vasodilators through lowering of afterload and subsequent improvement of failing left ventricle. ${ }^{10} 20$ If prostacyclin, indeed, finds application in the above clinical situations, then it might be advantageous in comparison with the currently used vasodilators, since its potentially useful haemodynamic effects occur even at low doses ( 2 to $10 \mathrm{ng} / \mathrm{kg}$ per min) which cause no serious side effects.

We thank The Upjohn Company for a grant for equipment.

\section{References}

1 Gryglewski RJ, Bunting S, Moncada S, Flower RJ, Vane JR. Arterial walls are protected against deposition of platelet thrombi by a substance (prostaglandin $\mathrm{X}$ ) which they make from prostaglandin endoperoxides. Prostaglandins 1976; 12: 685-713.

2 Moncada S, Gryglewski RJ, Bunting S, Vane JR. A lipid peroxide inhibits the enzyme in blood vessel microsomes that generates from prostaglandin endoperoxides the substance (prostaglandin $\mathrm{X}$ ) which prevents platelet aggregation. Prostaglandins 1976; 12: $715-37$.

3 Gryglewski RJ, Korbut R, Ocetkiewicz A. Generation of prostacyclin by lungs in vivo and its release into the arterial circulation. Nature 1978; 273: 765-7.

4 Szczeklik A, Gryglewski RJ. The actions of prostacyclin in man. In: Vane JR, Bergström S, eds. Prostacyclin. New York: Raven Press, 1979: 393-408.

5 Gryglewski RJ, Szczeklik A. Inhibition of prostacyclin formation by lipid peroxides in the arterial wall: hypothetical step in development of atherosclerosis. Mater Med Pol 1978; 37: 338-41.

6 Szczeklik A, Nizankowski R, Skawiński S, Szczeklik J, Gluszko P, Gryglewski RJ. Successful therapy of advanced arteriosclerosis obliterans with prostacyclin. Lancet 1979; i: 1111-4.

7 Weissler AM, Harris WS, Schoenfeld CD. Systolic time intervals in heart failure in man. Circulation 1968; 37: 149-59.

8 Parmley WW, Diamond G, Tomoda H, Forrester JS, Swan HJC. Clinical evaluation of left ventricular pressures in myocardial infarction. Circulation 1972; 45: 358-66.

9 Szczeklik A, Gryglewski RJ, Nizankowski R, Musial J, Pietoń R, Mruk J. Circulatory and antiplatelet effects of intravenous prostacyclin in healthy men. Pharmacol Res Commun 1978; 10 : 545-56.

10 Leffler CW, Hessler JR. Pulmonary and systemic vascular effects of exogenous prostaglandin $I_{2}$ in fetal lambs. Eur $\mathcal{F}$ Pharmacol 1979; 54: 37-42.

11 Spannhake EW, Chapnick BM, Feigen LP, et al. Pulmonary and systemic vasodilator effects of prostacyclin (abstract). Fed Proc 1978; 37: 731-5.

12 Armstrong JM, Lattimer N, Moncada S, Vane JR. 
Comparison of vasodepressor effects of prostacyclin and 6-oxo-prostaglandin $F_{1 \alpha}$ with those of prostaglandin $\mathrm{E}_{2}$ in rats and rabbits. Br $\mathcal{F}$ Pharmacol 1978; 62: $125-30$.

13 Fitzpatrick TM, Alter I, Corey EJ, Ramwell PW, Rose JC, Kot PA. Cardiovascular responses to $\mathrm{PGI}_{2}$ (prostacyclin) in the dog. Circ Res 1978; 42: 192-7.

14 Szczeklik J, Dubiel JS, Mysik M, Pyzik Z, Król R, Horzela $T$. Effects of prostaglandin $E_{1}$ on pulmonary circulation in patients with pulmonary hypertension. Br Heart f 1978; 40: 1397-401.

15 Olsson AG, Carlson LA. Clinical, hemodynamic and metabolic effects of intraarterial infusions of prostaglandin $\mathrm{E}_{1}$ in patients with peripheral vascular disease. In: Samuelsson B, Paoletti R, eds. Advances in prostaglandin and thromboxane research. Vol 1. New York: Raven Press, 1976: 429-31.

16 Kadowitz PJ, Chapnick, BM, Feigen LP, et al.
Pulmonary and systemic vasodilator effects of the newly discovered prostaglandin, $\mathrm{PGI}_{2}$. $\mathcal{f}$ Appl Physiol 1978; 45: 408-13.

17 Nowak J. Prostaglandins in the cardiovascular system in man. A biochemical and physiological study. Acta Physiol Scand 1979; suppl 467: 1-49.

18 Szczeklik A, Gryglewski RJ, Nizankowski R, Skawiński S, Gluszko P. Prostacyclin therapy in peripheral arterial disease. Thromb Res (in press).

19 Kelman GR. Applied cardiovascular physiology. 2nd ed. London: Butterworths, 1977.

20 Massie BM, Chatterjee K. Vasodilator therapy of pump failure complicating acute myocardial infarction. Med Clin North Am 1979; 63: 25-51.

Requests for reprints to Professor Andrzej Szczeklik, Institute of Internal Medicine, Skawinska 8, 31-066 Kraków, Poland. 